\title{
Interaction between Bond and Deviation Forces in Spalling Failures of Arch-Shaped Members without Transverse Reinforcement
}

\author{
by Miguel Fernández Ruiz, Sylvain Plumey, and Aurelio Muttoni
}

\begin{abstract}
This paper investigates the structural behavior of reinforced concrete $(R C)$ arch-shaped members without transverse reinforcement subjected to bending. Such members have typical applications in tunnels, cut-and-cover structures, shells, vaults, ducts, silos, tanks, and off-shore structures. Although such members are mostly subjected to axial forces, bending moments may also develop when the shape of the structure does not perfectly match the ideal funicular shape. In this case, when the intrados reinforcement is in tension, deviation forces developed by the reinforcement increase the splitting stresses originated by bond and can lead to spalling of the reinforcement cover. Such a failure mode is particularly brittle and dangerous, leading to a sudden loss of load-carrying capacity of the structure. In this paper, a series of six tests on $400 \mathrm{~mm}$ (15.7 in.) thick arch-shaped beams are presented. They are aimed at investigating spalling failures before and after yielding of the tensile reinforcement. These results, as well as others taken from the literature, were compared to an analytical model accounting for the interaction between bond and deviation forces, showing a good agreement and explaining the various failure modes observed. On that basis, a practical formula for the design of such members is proposed.
\end{abstract}

Keywords: aggregate size; concrete compressive strength; crack width; physical model; shear strength.

\section{INTRODUCTION}

In July 2004, the concrete cover of the Mitholz cut-andcover tunnel in Switzerland spalled off, forcing traffic to stop (refer to Fig. 1(a) and (b)). The cut-and-cover tunnel was arch-shaped without transverse reinforcement in the upper region and was opened to traffic in 2002. Prior to spalling of the concrete cover, the structure presented no significant warning signs (deflections and crack widths were low). As Fig. 1(c) shows, spalling developed at the region where the intrados reinforcement was in tension (due to the strongly asymmetric filling of the tunnel).

Structures with similar characteristics (arch-shaped members subjected to bending and axial forces) can also be found in tunnels, pipes, shells, vaults, ducts, silos, tanks, and off-shore structures when nonsymmetrical loads are applied. All of them can potentially develop cover spalling failures in case no transverse reinforcement is provided and when the intrados reinforcement is in tension. Also, failures in curved bridges with spalling in the webs of the lateral concrete cover of post-tensioning tendons (due to horizontal prestressing deviation forces) have been reported by Podolny. ${ }^{1}$

Cover spalling failures in arch-shaped members are in general originated by the combination of two phenomena. The first one is the transverse tensile stresses due to the deviation forces of a curved reinforcement (Fig. 2). The second one is the tensile splitting stresses originated by the bond of deformed reinforcement (Fig. 3). Both the deviation and splitting tensile stresses depend on the level of stresses of the reinforcement and develop in the same region close to the reinforcing bar (Fig. 2(b) and 3(c)). Researches on the topic of cover spalling of arched-shaped members have been developed in the past in Germany ${ }^{2-5}$ and Austria. ${ }^{6,7}$ Scanty experimental data, however, are still available and the influence of the previous phenomena is not always explicitly considered in the design of arch-shaped members without transverse reinforcement. ${ }^{8,9}$

The typical design approach with respect to this problem ${ }^{10,11}$ considers that the transverse tensile forces per unit length $q_{t r}$ (usually reference is only made to deviation

(a)

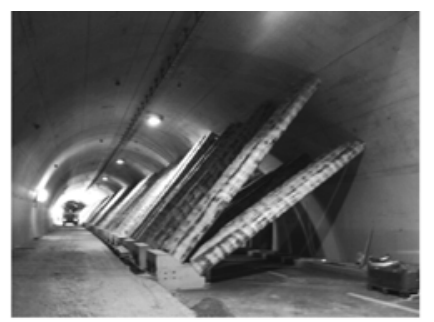

(b)

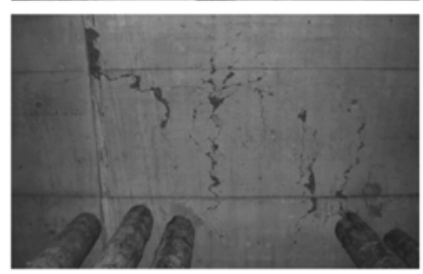

(c)

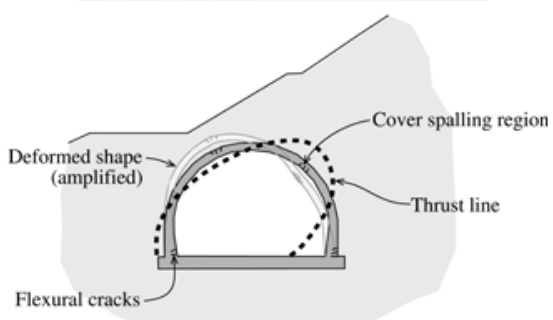

Fig. 1-Concrete cover spalling of arched-shaped cut-andcover tunnel (Mitholz, Switzerland, 2004): (a) view of cutand-cover strengthening after cover spalling; $(b)$ detail of cover spalling; and (c) geometry of Mitholz cut-and-cover tunnel, filling, and zone of concrete cover spalling.

ACI Structural Journal, V. 107, No. 3, May-June 2010.

MS No. S-2009-086.R1 received March 19, 2009, and reviewed under Institute publication policies. Copyright (C) 2010, American Concrete Institute. All rights reserved, including the making of copies unless permission is obtained from the copyright proprietors. Pertinent discussion including author's closure, if any, will be published in the MarchApril 2011 ACI Structural Journal if the discussion is received by November 1, 2010. 
Miguel Fernández Ruiz is a Lecturer and Research Scientist at École Polytechnique Fédérale de Lausanne (EPFL), Lausanne, Switzerland. He received his diploma in civil engineering and his PhD from the Polytechnical University of Madrid, Madrid, Spain, in 2001 and 2004, respectively. His research interests include the serviceability behavior of structures, bond, shear, and the modeling of structural concrete using stress fields.

Sylvain Plumey is a Structural Engineer at Buchs \& Plumey, St-Ursanne, Switzerland. He received his diploma in civil engineering from EPFL in 2002. From 2002 to 2007, he performed his PhD studies at EPFL and developed the experimental work presented in this paper. His research interests include cut-and-cover tunnels, soil-structure interaction, shear, and the fundamentals of the theory of plasticity.

ACI member Aurelio Muttoni is a Professor and Head of the Structural Concrete Laboratory at EPFL. He received his diploma and PhD in civil engineering from the Swiss Federal Institute of Technology, Zurich, Switzerland, in 1982 and 1989, respectively. His research interests include the theoretical basis of the design of reinforced concrete structures, shear and punching shear, fiber-reinforced highstrength concrete, soil-structure interaction, and the conceptual design of bridges.

forces and suspension forces [loads hanging from the intrados of the member]) has to be smaller or equal to the strength calculated using a reduced tensile strength $k \cdot f_{c t d}$ acting over an effective width $b_{e f}$ (refer to Fig. 2(b))

$$
k \cdot f_{c t d} \cdot b_{e f} \geq q_{t r}
$$

where $f_{c t d}$ is the design concrete tensile strength (refer to Notation section for details). Proposed values for coefficient $k$ are, for instance, $0.50,0.33$, and 0.29 according to the Swiss Code, ${ }^{10}$ the Austrian Code, ${ }^{11}$ and Intichar et al., ${ }^{7}$ respectively. These values of coefficient $k$ consider that spalling failures should develop after yielding of the reinforcement, and thus (in case no suspension forces are applied)

$$
k \cdot f_{c t d} \cdot b_{e f} \geq \frac{f_{y d} \cdot \pi / 4 \cdot d_{b}^{2}}{R}
$$

Such an approach is very convenient when the internal forces of a structure are calculated from an elastic analysis, as usually performed in the design of new structures. No information, however, is given about the behavior of the member after yielding and of its deformation capacity. This makes the application of this approach more difficult for plastic analyses accounting for the redistribution of internal forces (typically performed when assessing the strength of an existing structure) or for analysis considering soilstructure interaction where the action exerted by the soil depends on the deformation capacity of the structure. Also, the role of bond stresses or the influence of lap splices is not explicitly addressed in this approach.

In this paper, the results of six tests performed on archshaped members are presented. These tests complete those available in the scientific literature investigating failures before and after yielding of the reinforcement as well as failures in the presence of lap splices. Based on the experimental observations, a consistent approach is introduced to investigate spalling failures of arch-shaped members. The model accounts both for deviation and bond forces of the reinforcement, allowing to correctly reproduce the various experimental results.

\section{RESEARCH SIGNIFICANCE}

Reinforcement cover spalling is in many cases the governing failure mode for arch-shaped members without transverse reinforcement and where the intrados reinforcement is in tension. Such a failure mode is brittle and leads to a total (a)

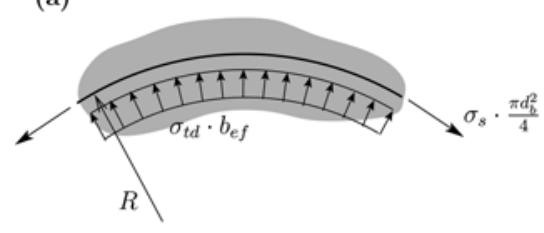

(b)

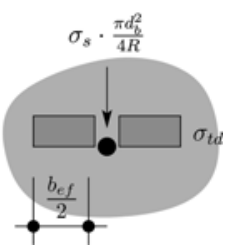

Fig. 2-Equilibrium of deviation forces of curved reinforcement: (a) longitudinal view; and (b) tensile stresses (assuming constant tensile stress in concrete). (a)

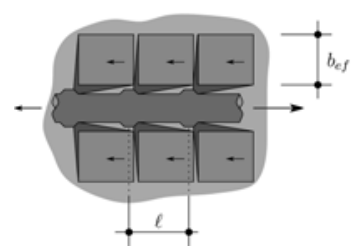

(b)

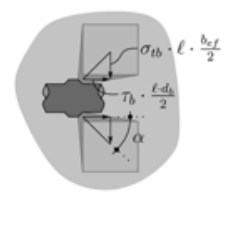

(c)

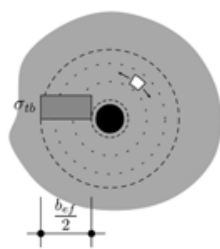

Fig. 3-Bond splitting stresses: (a) tension rings around reinforcement bar; (b) equilibrium of longitudinal forces; and (c) transverse tensile stresses assuming constant value of stress in tension ring.

loss of the load-carrying capacity. Little research has been performed in the past on this topic and many codes do not provide guidelines for its design. This paper presents the results of six tests investigating failures before and after yielding of the flexural reinforcement as well as the influence of lap splices on their strength. The experimental results, together with others taken from the scientific literature, are used to formulate a physical model describing the various failure modes observed and leading to a simple design formula for such members.

\section{Specimens}

\section{EXPERIMENTAL PROGRAM}

Six curved beams with a varying flexural reinforcement ratio were tested by the authors. ${ }^{12}$ The specimens (refer to Fig. 4) had a rectangular cross section of $300 \times 400 \mathrm{~mm}$ (width times height, $11.8 \times 15.8$ in.), with a span of $4600 \mathrm{~mm}$ (181 in.). The inner radius of the beams was $3500 \mathrm{~mm}$ (138 in.) and the cover thickness of the flexural reinforcement was $40 \mathrm{~mm}$ (1.58 in.). The curved flexural reinforcement is named circumferential reinforcement hereafter.

The beams were loaded under a four-point bending system (Fig. 4), with a distance between the axes of applied loads equal to $2400 \mathrm{~mm}$ (94.5 in.). In the constant moment region, a set of bars perpendicular to the circumferential reinforcement was also provided to reproduce the actual reinforcement layout of these members.

Four specimens (ECP1-4) had continuous bars without lap splices, with the aim of investigating concrete cover spalling before and after yielding of the flexural reinforcement. The circumferential reinforcement ratio $\left(\rho=A_{s} / A_{c}\right)$ was thus varied between 1.53 and $0.72 \%$ (Table 1). In Specimen ECP5, the flexural reinforcement was spliced providing conventional lap lengths equal to 40 times the diameter of the bar (curved bars, total horizontal lap length $880 \mathrm{~mm}$ [34.6 in.]) (refer to Table 1). The same lap length was provided in test ECP6 but the bars were kept straight at the 

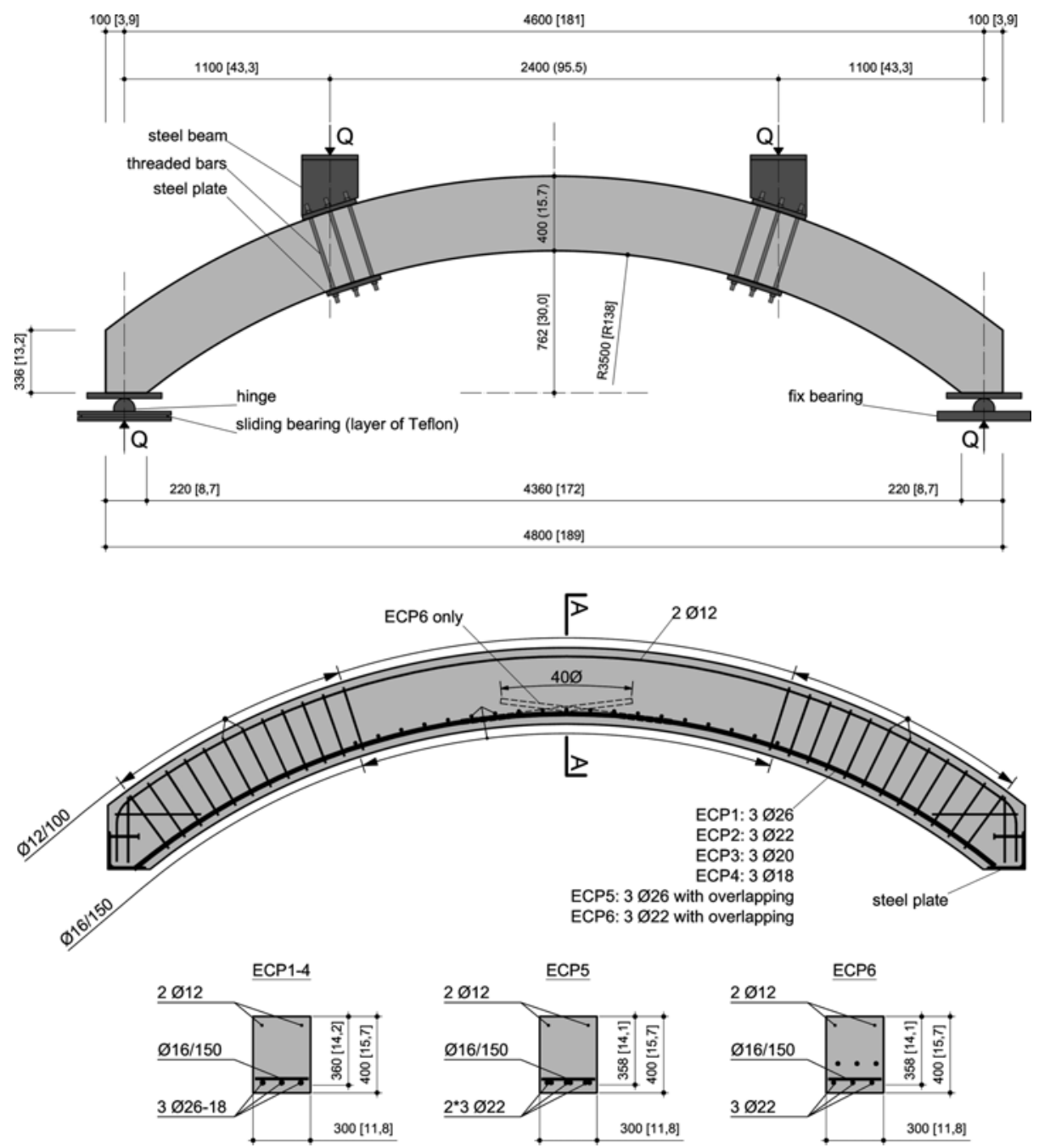

Fig. 4-Geometry and reinforcement layout of specimens (dimensions in mm [in.]): Specimens ECP1-4 without lap splices, Specimen ECP5 with curved lap splices, and Specimen ECP6 with straight lap splices).

splice region. The aim of the latter specimen was to reduce the deviation forces in the splice region.

The loads were introduced by means of two wedge-shaped steel profiles (Fig. 4) and were increased progressively up to failure using a hand-controlled hydraulic pump.

\section{Material properties}

The specimens were cast in two batches with normal strength concrete. The maximum aggregate size was $32 \mathrm{~mm}$ (1.26 in.). Its compressive strength at the time of testing ranged between 33.9 and $41.7 \mathrm{MPa}$ (4900 and $6000 \mathrm{psi}$ ). More details are given in Table 1.

The steel used for the longitudinal reinforcement was hotrolled with a well-defined yield plateau (yield strength ranging between 520 and $613 \mathrm{MPa}$ [75.4 and $88.9 \mathrm{ksi}$ ]) (refer to Table 1). The measured modulus of elasticity for all bars was approximately $205 \mathrm{GPa}(29,700 \mathrm{ksi})$.

\section{Measurements}

The vertical displacement of the beam was measured at five points over the inner part of the beam (between the points of application of the loads [refer to Fig. 5]) using linearly variable displacement transducers (LVDTs).
Surface measurements were also made on one of the lateral surfaces of the specimens using omega-shaped extensometers. Two sets of 19 and 17 omega-shaped gages were glued at the concrete surface at $50 \mathrm{~mm}$ (1.97 in.) of the top and bottom surfaces of the specimen, respectively (refer to Fig. 5). The measurement base of the gauges was $100 \mathrm{~mm}$ (3.93 in.).

\section{Development of tests}

Figure 6(a) plots the load versus midspan deflection recorded for all tests. Specimens ECP1, 5, and 6 failed before yielding of the flexural reinforcement. On the contrary, Specimens ECP2-4 developed a well-defined yield plateau.

In the investigated region (with constant bending moment) the flexural cracks were located for all specimens at the position where the bars perpendicular to the circumferential reinforcement were provided. Prior to failure, small cracks parallel to the circumferential reinforcement were also observed locally on the lateral surfaces of the specimens at the level of the reinforcement. Measurements on the specimens developing plastic strains (ECP2-4) showed that such cracks initiated at the positions of maximum strains at the level of the circumferential reinforcement (refer to the measurements on concrete surface in Fig. 6(b)). Failure occurred in all specimens in a 
Table 1-Main properties of tested specimens

\begin{tabular}{|c|c|c|c|c|c|c|c|}
\hline Specimen & $\begin{array}{c}f_{c}, \mathrm{MPa} \\
(\mathrm{psi})\end{array}$ & $\begin{array}{c}E_{c}, \mathrm{GPa} \\
(\mathrm{ksi})\end{array}$ & $\begin{array}{c}f_{y}, \mathrm{MPa} \\
(\mathrm{ksi})\end{array}$ & $\begin{array}{c}d_{b}, \mathrm{~mm} \\
\text { (in.) }\end{array}$ & $\rho, \%$ & Lap splices & $\begin{array}{c}Q_{R} \mathrm{kN} \\
\text { (kips) }\end{array}$ \\
\hline ECP1 & $\begin{array}{c}37.4 \\
(5420)\end{array}$ & $\begin{array}{c}32.2 \\
(4670)\end{array}$ & $\begin{array}{c}613 \\
(88.9)\end{array}$ & $\begin{array}{c}26 \\
(1.02)\end{array}$ & 1.53 & No & $\begin{array}{c}432 \\
(97.1)\end{array}$ \\
\hline ECP2 & $\begin{array}{c}40.9 \\
(5930)\end{array}$ & $\begin{array}{c}34.0 \\
(4931)\end{array}$ & $\begin{array}{c}520 \\
(75.4)\end{array}$ & $\begin{array}{c}22 \\
(0.87)\end{array}$ & 1.09 & No & $\begin{array}{c}324 \\
(72.8)\end{array}$ \\
\hline ECP3 & $\begin{array}{c}41.7 \\
(6050)\end{array}$ & $\begin{array}{c}33.5 \\
(4859)\end{array}$ & $\begin{array}{c}531 \\
(77.0)\end{array}$ & $\begin{array}{c}20 \\
(0.79)\end{array}$ & 0.90 & No & $\begin{array}{c}287 \\
(64.5)\end{array}$ \\
\hline ECP4 & $\begin{array}{c}33.9 \\
(4920)\end{array}$ & $\begin{array}{c}30.2 \\
(4380)\end{array}$ & $\begin{array}{c}541 \\
(78.5)\end{array}$ & $\begin{array}{c}18 \\
(0.71)\end{array}$ & 0.72 & No & $\begin{array}{c}231 \\
(51.9)\end{array}$ \\
\hline ECP5 & $\begin{array}{c}38.4 \\
(5570)\end{array}$ & $\begin{array}{c}34.7 \\
(5030)\end{array}$ & $\begin{array}{c}600 \\
(87.0)\end{array}$ & $\begin{array}{c}22 \\
(0.87)\end{array}$ & 1.09 & & $\begin{array}{c}237 \\
(53.7)\end{array}$ \\
\hline ECP6 & $\begin{array}{c}35.5 \\
(5150)\end{array}$ & $\begin{array}{c}30.7 \\
(4453)\end{array}$ & $\begin{array}{c}600 \\
(87.0)\end{array}$ & $\begin{array}{c}22 \\
(0.87)\end{array}$ & 1.09 & & $\begin{array}{c}197 \\
(44.3)\end{array}$ \\
\hline
\end{tabular}

brittle manner by a sudden propagation and opening of these cracks parallel to the circumferential reinforcement (Fig. 7).

\section{Tests without lap splices}

Specimens ECP2-4 (whose flexural reinforcement yielded prior to failure) did not develop cracks on the bottom face of the members parallel to the circumferential direction. On the contrary, Specimen ECP1 (failure without yielding of the flexural reinforcement) presented a well-defined splitting crack on the bottom face of the member in this direction.

Figure 6(b) shows the maximum deformation measured by the omega-shaped gauges at the level of the longitudinal reinforcement for Specimens ECP1-4. A clear correlation between the applied load and the maximum recorded strain at the concrete surface is shown, with increasing strains for decreasing levels of applied load. The tests also indicate that the ductility (deflection) tends to decrease as the deviation forces on the flexural reinforcement increase. A direct correlation between the level of applied load and deflection after yielding is not evident, however. This is justified because failure developed locally (by propagation of a horizontal crack at the position where maximum strains were recorded in the reinforcement), and the strains in the bars after yielding are particularly sensitive to a number of bonddependent parameters ${ }^{13}$ : position of the crack with respect to lugs, bar diameter, size of the lugs, and steel type. For instance, Fig. 6 shows that the midspan deflection of ECP4 at failure was smaller than that of ECP3, although its maximum measured longitudinal strain was larger.

\section{Tests with lap splices}

The observed behavior of Specimen ECP5 (with lap slices) was very similar to that of Specimen ECP1 (with continuous reinforcement). Failure occurred by sudden spalling of the concrete cover when the reinforcement was still elastic. Compared to Specimen ECP2 (with the same flexural reinforcement ratio but without splices and where the strength was governed by yielding of the flexural reinforcement) the strength was reduced by $27 \%$. This indicates that the local increase of bond stresses at the splice region is detrimental to the strength of the member (in accordance with the investigations by Intichar $^{6}$ ). Furthermore, the deflection of Specimen ECP5 at failure (measured at midspan) was only $43 \%$ of that of Specimen ECP2 (Fig. 6(a)).

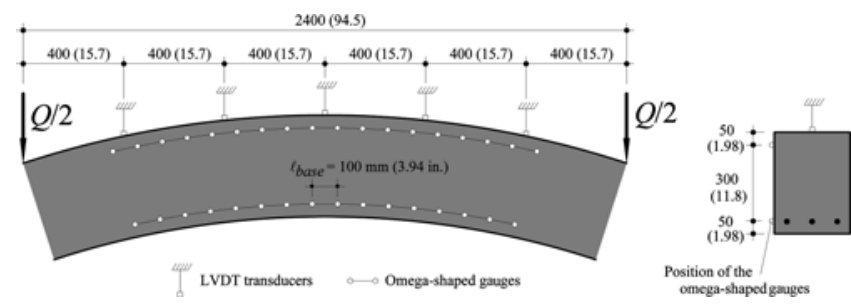

Fig. 5-Positions of LVDTs and omega-shaped gauges. (Note: Dimensions are in mm [in.].)
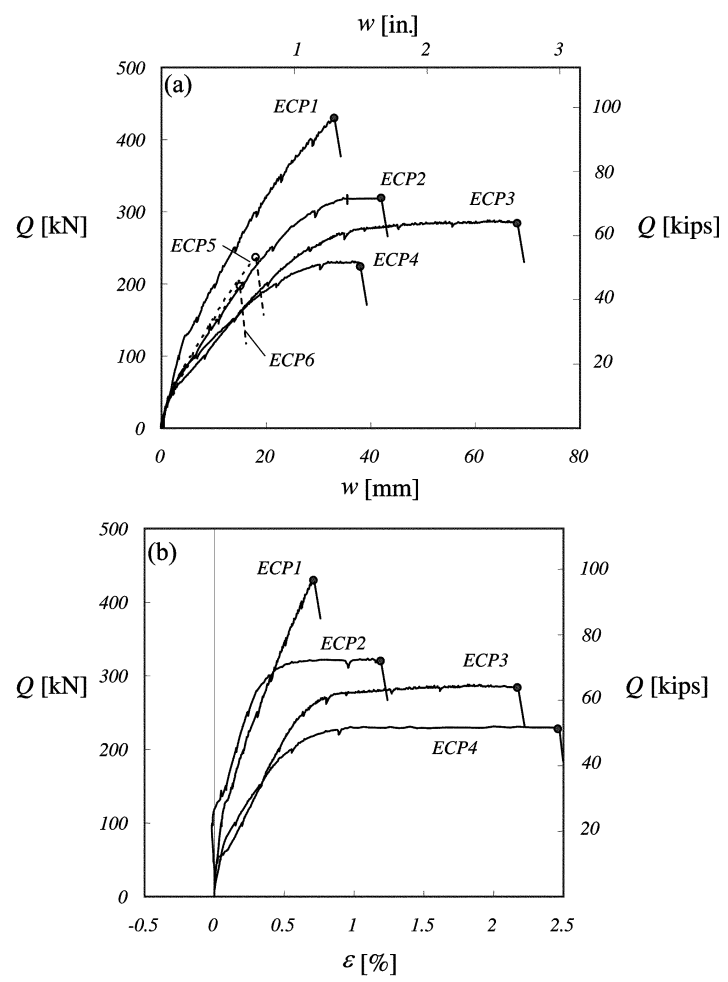

Fig. 6-Behavior of tested specimens: (a) plots of applied load versus midspan deflection; and (b) plots of applied load versus maximum strain measured on concrete surface at level of circumferential reinforcement (omega-shaped gauges).

The mode of failure observed for Specimen ECP6 was different to that of Specimens ECP1-5. Instead of spalling of the concrete cover, failure was originated by the development of three almost horizontal cracks in the central region of the specimen (suggesting a development failure of the flexural reinforcement) (Fig. 7). Failure was nevertheless brittle and was followed by a total loss of load-carrying capacity. This lap splicing detail performed worse than the conventional detail in Specimen ECP5, with a smaller failure load and recorded deflection at failure (with reductions of approximately $20 \%$ ).

\section{INTERACTION BETWEEN BOND AND DEVIATION FORCES ON ARCH-SHAPED MEMBERS}

As previously mentioned, and confirmed by the tests presented, cover spalling of arch-shaped members is due to the combination of bond-splitting forces and deviation forces of the reinforcement (refer to spalling failures after yielding and the detrimental effect of lap splices). The stress state at that region (Fig. 8) is rather complicated as it is influenced by a number of parameters such as the distance between bars, the ratio between splitting and deviation forces, the concrete cover, the 


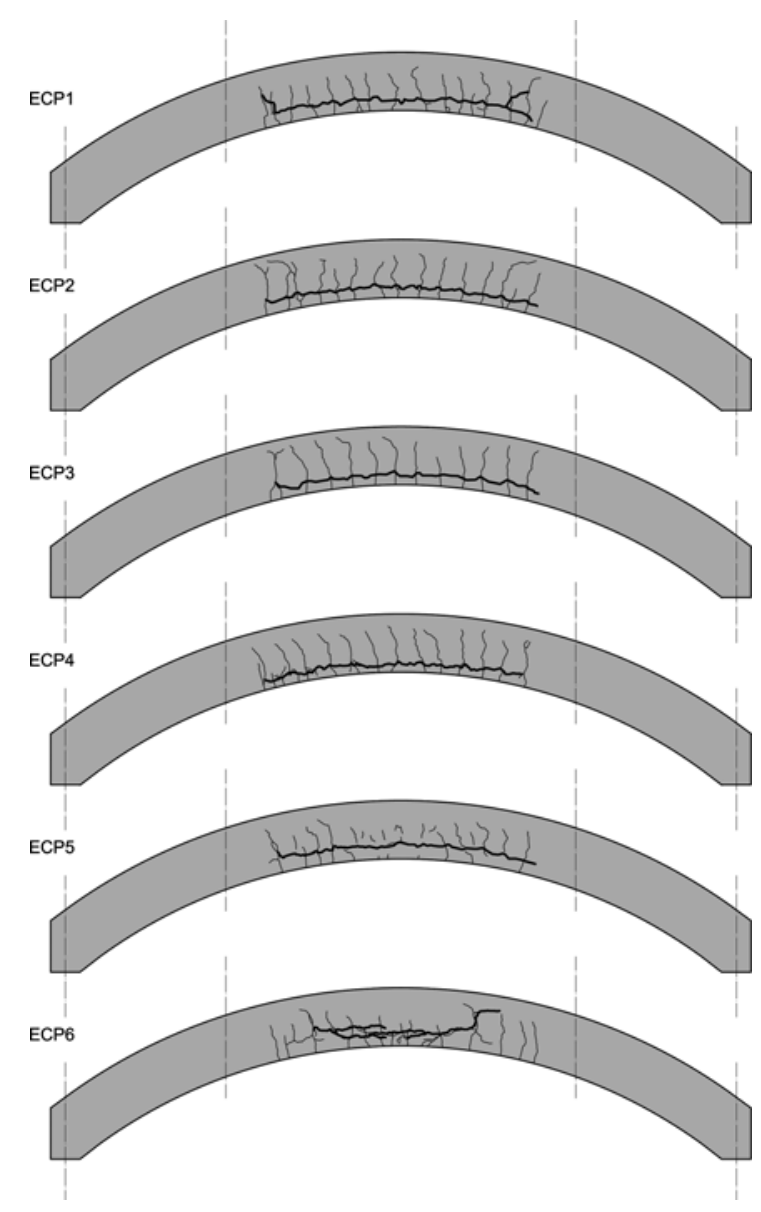

Fig. 7-Cracking pattern of Specimens ECPI-6 after failure.

presence of transverse reinforcement, and others. ${ }^{14}$ Assuming that failure develops on a surface parallel to the reinforcement layer (applications to other failure surfaces will be discussed in a following section) the stress distribution can be represented in a simplified way by adopting a constant stress (equal to a reduced tensile strength: $\eta \cdot f_{c t}$ ) active over an effective width $b_{e f}$ (refer to Appendix 1) (Fig. 8(c)). It can be noted that coefficient $\eta$ accounts only for concrete brittleness in tension, contrary to coefficient $k$ used in Eq. (1) and (2), which also considers the influence of the longitudinal strains of the bar (as it will be discussed in a following section).

Thus, the tensile stress in concrete at the failure $\sigma_{t}$ can be calculated as the sum of the tensile stress originated by the deviation forces $\sigma_{t d}$ plus the tensile stress due to bond splitting forces $\sigma_{t b}$. The first term $\sigma_{t d}$ can be obtained considering equilibrium conditions (Fig. 2) as

$$
\sigma_{t d}=\sigma_{s} \frac{\pi / 4 \cdot d_{b}^{2}}{b_{e f} \cdot R}
$$

The second term $\sigma_{t b}$ can also be obtained through equilibrium conditions (Fig. 3), as ${ }^{15}$

$$
\sigma_{t b}=\tau_{b} \cdot \frac{\tan (\alpha) \cdot d_{b}}{b_{e f}}
$$

thus, the total tensile stress results

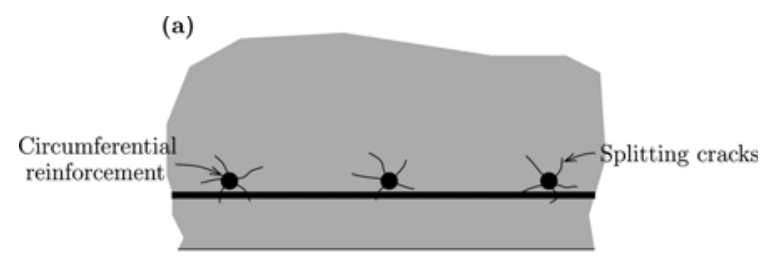

(b)

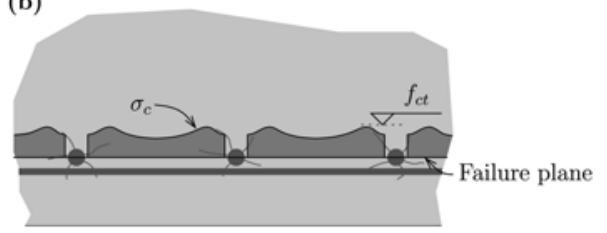

(c)

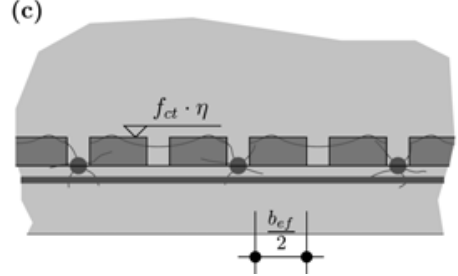

Fig. 8-Tensile stresses at concrete between two reinforcing bars: (a) investigated region and splitting (bond) cracks; (b) actual tensile stresses developed in concrete; and (c) assumed (simplified) state of stresses.

$$
\sigma_{t}=\sigma_{s} \frac{\pi / 4 \cdot d_{b}^{2}}{b_{e f} \cdot R}+\tau_{b} \cdot \frac{\tan (\alpha) \cdot d_{b}}{b_{e f}}
$$

This formula allows considering both the influence of deviation and bond forces on the splitting stresses at the failure surface. Equation (5) is used on Appendix 1 to derive an analytical expression that can be used to calculate the failure load of arch-shaped members on the basis of the affinity hypothesis for bond. ${ }^{13,16}$

The suitability of Eq. (5) for predicting failures of archshaped members (using the formulas of Appendix 1) is compared in Fig. 9(a) to 34 test results (comprising those presented in this paper as well as others taken from the scientific literature ${ }^{2,6}$ and whose main geometrical parameters are shown in Fig. 10(a) and (b). More details of this comparison can be found in Table 2 of Appendix 1. The results of the theoretical model show a good agreement to test results, with a small value of the coefficient of variation.

The influence of the reinforcement strains on the spalling strength of arch-shaped members can also be appreciated in Fig. 9(b). This figure shows the value of coefficient $k$ (refer to Eq. (1)) as a function of the reinforcement strain for the previous tests as well as those performed by Neuner and $\mathrm{Stöckl}^{4}$ (refer to Fig. 10(c)). Those tests were performed on specimens with straight bars, where spalling of the cover developed by shearing of the reinforcing bars. The strains in Fig. 9(b) are calculated for specimens failing prior to yielding of the reinforcement by introducing the measured failure load into Eq. (12) (refer to Appendix 1). For specimens where failure develops after yielding, the longitudinal strains of the bars are obtained from measured data (tests by Plumey ${ }^{12}$ ) or assumed to be twice the yield strain (tests by Franz and Fein ${ }^{2}$ ). The plot shows that the value of coefficient $k$ depends strongly on the level of strains of the longitudinal 
reinforcement. This is logical because splitting bond stresses increase for larger strains in the bar, even after yielding. For instance, for tests where failure develops prior to yielding of the reinforcement, $95 \%$ of tests remain above the value $k_{e l}=$ $1 / 4$, whereas for tests where failure developed after yielding of the flexural reinforcement, $95 \%$ of the tests remained above the value $k_{p l}=1 / 6$ (Fig. 9(b)).

\section{CODE-LIKE PROPOSAL}

For design purposes, it can be noted that the approach adopted by codes of practice in reducing the effective tensile strength by a factor $k$ (Eq. (1) and (2)) is rather practical. As previously discussed, the value of factor $k$ accounts for bar strains (refer to Fig. 9(b)) and significant differences in the spalling strength are found between specimens whether the flexural reinforcement yields or not. Thus, design based on this coefficient should distinguish:

1. Cases where a significant deformation capacity is required (with development of plastic strains). Based on the tests reported in this paper, a reasonable and safe value for design is $k_{p l}=1 / 6$.

2. Cases where no particular deformation capacity is required and where the internal efforts are obtained from an elastic analysis. In this case, also based on the tests presented in this paper, a first and safe estimate for design is $k_{e l}=1 / 4$. In cases where a more refined estimate is required, it can be considered that spalling of the concrete cover does not develop prior to yielding of the reinforcement. Thus, the design value of $k_{e l}$ can be obtained by introducing Eq. (10) (refer to Appendix 1) into Eq. (2) and considering that failure develops at yielding $\left(\sigma_{s}=f_{y d}, \sigma_{t}=\eta f_{c t d}\right)$

$$
k_{e l}=0.8-2.5 \frac{d_{b}}{b_{e f}} \kappa_{b}
$$

where, according to Appendix $1, \kappa_{b}$ is a coefficient whose value is equal to 1 or $\sqrt{ } 2$ in the presence of lap splices and $b_{e f}=$ $s-d_{b} \leq \min \left(6 d_{b} ; 4 c\right)$, where $s$ is the distance between the circumferential reinforcement.

It can be noted in Eq. (6) that coefficient $k_{e l}$ increases for small bar diameters and large values of the concrete cover and bar spacing. This is logical because the transverse tensile stresses around the bar will be lower. It also accounts for the presence of splices decreasing, in such a case, the value of $k_{e l}$ (refer to coefficient $\kappa_{b}$ ). It can also be noted that, accounting for the limits set for $b_{e f}$, the value of $k_{e l}$ will always be lower or equal to 0.38 (a value in between those proposed by the Swiss ${ }^{10}$ and the Austrian codes, ${ }^{11}$ respectively).

According to Eq. (2), spalling of the concrete cover will thus not develop prior to yielding if

$$
k_{e l} f_{c t d} b_{e f} \geq \frac{f_{y d} \pi / 4 d_{b}^{2}}{R}
$$

where $f_{y d}$ is the design yield strength of the reinforcing steel.

\section{INTERACTION OF TRANSVERSE TENSION WITH OTHER ACTIONS}

The phenomenon of cover spalling is also influenced by other actions such as suspended loads, ${ }^{7}$ prestressing, ${ }^{1}$ and shear forces. With respect to shear forces, the interaction with cover spalling is relevant and complex. ${ }^{7}$ A way to
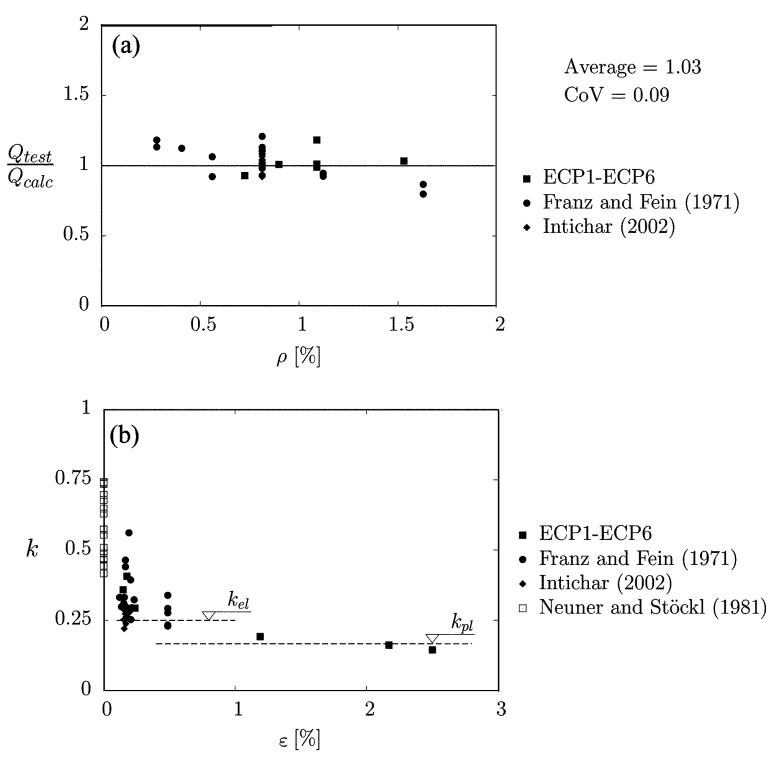

Fig. 9-Comparison to test data: (a) comparison between measured and predicted failure loads for tests ECP1 to 6, tests of Franz and Fein ${ }^{2}$ and Intichar ${ }^{6}$ as function of flexural reinforcement ratio; and (b) coefficient $\mathrm{k}$ as function of longitudinal reinforcement strains.
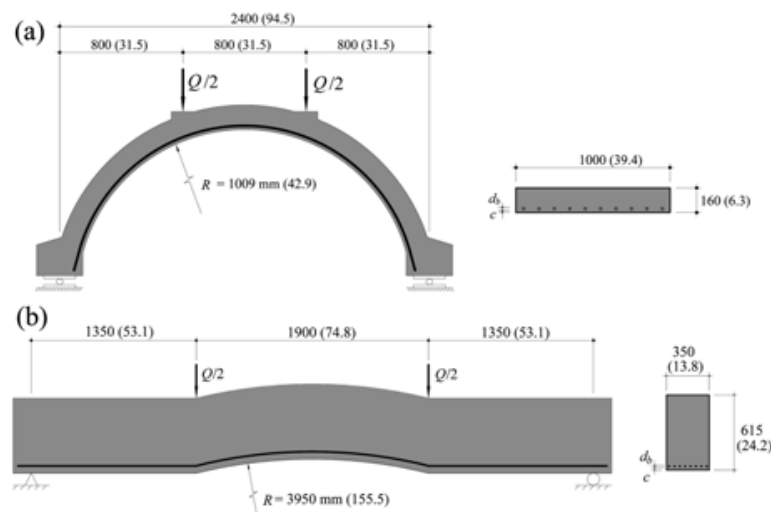

(c)

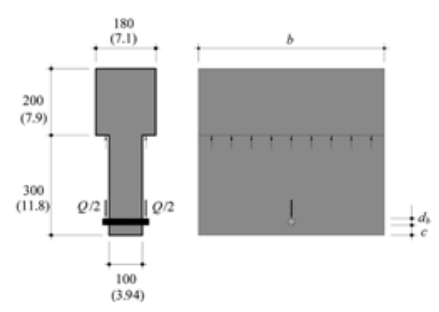

Fig. 10-Geometry (dimensions in mm [in.]) of the tests by: (a) Franz and Fein ${ }^{2}$; (b) Intichar ${ }^{6}$; and (c) Neuner and Stöckl. ${ }^{4}$

introduce this interaction consistently with the approach presented in this paper and the critical shear crack theory ${ }^{17}$ is currently being investigated by the authors of this paper.

\section{CONCLUSIONS}

This paper investigates concrete cover spalling of archedshaped members without transverse reinforcement subjected to axial forces and bending moments. The main conclusions of the paper are:

1. Spalling of the concrete cover can be the governing failure mode of such members. 
2. Spalling of the concrete cover is influenced by both deviation forces and bond-splitting stresses.

3. Failures are possible even after yielding of the flexural reinforcement because bond stresses increase due to the wedging action of the ribs. Such failures may significantly limit the rotation capacity of arch-shaped members.

4. A mechanical model accounting for bond stresses and deviation forces is a consistent approach for investigating this phenomenon. On this basis, and using the affinity hypothesis for bond, a formula is derived with an excellent agreement to test results.

5. This approach allows the consideration of the detrimental influence of lap splices on the spalling strength of such members, suitably reproducing the results of the tests performed within this research.

6 . The proposed approach, rewritten in the format usually adopted by codes of practice, leads to a simple design expression. This expression distinguishes between failures prior to and after yielding of the reinforcement and allows the consideration of the influence of bar diameter, bar spacing, cover thickness, and the presence of lap splices.

\section{ACKNOWLEDGMENTS}

The authors wish to acknowledge the support and funding of the Swiss Federal Road Authority and of the École Polytechnique Fédérale de Lausanne which made this research possible, as well as the help of J. A. Antonio Bardales Cofiño during the experimental work.

\section{NOTATION}$$
b \quad=\text { width of specimen }
$$

$b_{\text {ef }}=$ effective width

$c=$ concrete cover

$d \quad=$ distance from extreme compression fiber to centroid of longitudinal tensile reinforcement

$d_{b_{*}}=$ bar diameter

$d_{b} \quad=$ equivalent bar diameter

$E_{c} \quad=$ modulus of elasticity of concrete

$E_{s} \quad=$ modulus of elasticity of steel

$f_{c}=$ compressive strength of concrete (measured in cylinder)

$f_{c}^{\prime}=$ specified compressive strength of concrete

$f_{c k}=$ characteristic compressive strength of concrete (measured in cylinder)

$f_{c t}=$ concrete tensile strength at time of testing measured on cylinder if available or estimated as $0.30 f_{c}^{2 / 3}$ (MPa) $\left(f_{c t}=1.57 f_{c}^{2 / 3}[\mathrm{psi}]\right)$

$f_{\text {ctd }}=$ concrete design tensile strength; this value can be estimated as $0.21 \cdot f_{c k}^{2 / 3} / \gamma_{c}(\mathrm{MPa})\left(f_{c t d}=1.10 f_{c}^{, 2 / 3} \cdot \phi_{c}[\mathrm{psi}]\right)$

$f_{t} \quad=$ tensile strength of steel

$f_{y} \quad=$ yield strength of steel

$f_{y d}=$ design yield strength of steel $\left(f_{y k} / \gamma_{s} \approx \phi_{s} \cdot f_{y}\right.$ according to European and American practices, respectively)

$f_{y k}=$ characteristic yield strength of steel

$k=$ concrete tensile strength reduction factor accounting for concrete brittleness and bond

$k_{e l}=$ concrete tensile strength reduction factor before yielding of flexural reinforcement

$k_{p l}=$ concrete tensile strength reduction factor after yielding of flexural reinforcement

$M_{R} \quad=$ bending moment at failure

$M_{y}=$ plastic moment

$n_{b} \quad=$ number of bundled bars

$Q_{\text {calc }}=$ calculated failure load

$Q_{R} \quad=$ applied load at failure

$Q_{\text {test }}=$ measured failure load

$q_{t r} \quad=$ transverse force per unit length

$R \quad=$ radius of curvature of reinforcing bar

$=$ bar spacing

$=$ height of compression zone

$=$ angle of bond compressive struts with respect to bar axis

$=$ steel strain

$=$ yield strain of steel

$=$ strength reduction factor of concrete $\left(=1 / \gamma_{c}=0.67\right)$

$=$ strength reduction factor of steel $\left(=1 / \gamma_{s}=0.87\right)$

$=$ efficiency factor for concrete in tension

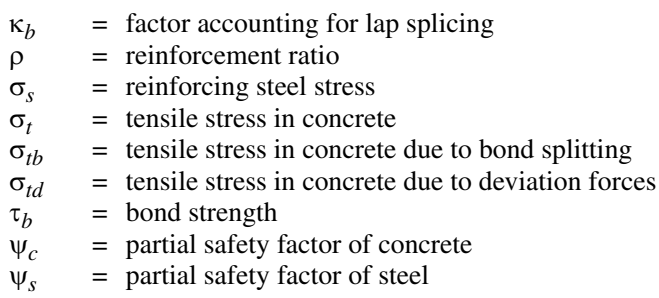

\section{REFERENCES}

1. Podolny, W., "The Cause of Cracking in Post-Tensioned Concrete Box Girder Bridges and Retrofit Procedures," PCI Journal, V. 30, No. 2, 1985, pp. 82-139.

2. Franz G., and Fein H. D., "Tests on R/C Culvert and Tunnel Lining," 2nd test series ("Betonversuche mit Baustahlgewebe-Bewehrungen für Rohre und Tunnelverkleidungen, Versuchsreihe 2"), Baustahlgewebe Berichte aus Forschung und Technik, Heft 8, Düsseldorf-Oberkassel, Germany, 1971, 52 pp. (in German)

3. Fein, H. D., and Zwissler, U., "Accomodating Deviation Forces of Curved Reinforcing Bars with Concrete" ("Aufnahme von Umlenkkräften aus stetig gekrümmten Bewehrungsstäben durch den Beton"), Die Bautechnik, V. 51, Heft 2, Berlin, Germany, Feb. 1974, pp. 58-61. (in German)

4. Neuner J., and Stöckl, S., "Research on Accommodating Deviation Forces of Curved Reinforcing Bars with Concrete Cover and Stirrups" ("Versuche zur Aufnahme der Umlenkkräfte von gekrümmten Bewehrungsstäben durch Betondeckung und Bügel"), Deutscher Ausschuss für Stahlbeton, Heft 322, Berlin-München, Germany, 1981, pp. 71-106. (in German)

5. Neuner, J., Theoretical Research on Accommodating Deviation Forces of Curved Reinforcing Bars with Concrete Cover and Stirrups (Theoretische Untersuchungen zur Aufnahme der Umlenkkräfte von gekrümmten Bewehrungsstäben durch Betondeckung und Bügel), Technische Universität München, Institut für Bauingenieurwesen III, Lehrstuhl für Massivbau, München, Germany, 1983, 30 pp. (in German)

6. Intichar, M., Investigation on the Interaction between Bond Stresses and Deviation Stresses (Untersuchung der Interaktion zwischen Verbundspannungen und Umlenkspannungen), Technische Universität Graz, Insitut für Betonbau, Graz, Austria, Sept. 2002, 95 pp. (in German)

7. Intichar, M.; Ebner, M.; and Sparowitz, L., Deviation Forces in Curved Beams (Umlenkkräfte in gekrümmten Stahlbetonbalken), Österreichische Ingenieur-und Architekten-Zeitschrift, V. 149, No. 1, Austria, 2004, pp. 11-16.

8. ACI Committee 318, "Building Code Requirements for Structural Concrete (ACI 318-08) and Commentary," American Concrete Institute, Farmington Hills, MI, 2008, 473 pp.

9. BS EN 1992-1-1: 2004, "Eurocode 2: Design of Concrete Structures: General Rules and Rules for Buildings," Brussels, Belgium, 2004, 225 pp.

10. SIA, "Code 262 for Concrete Structures," Swiss Society of Engineers and Architects, Zürich, Switzerland, 2003, 94 pp.

11. ÖNORM B 4700, "Reinforced Concrete Structures-EurocodeOrientated Analysis, Design and Detailing," 2001-06-01, Österreichisches Normungsinstitut, Wien, Austria, 2001, 106 pp.

12. Plumey, S., "Soil-Structure Interaction in Cut-and-Cover Tunnels ("Interaction Sol-Structure dans le Domaine des Tranchées Couvertes), Ecole Polytechnique Fédérale de Lausanne, PhD thesis No. 3714, Lausanne, Switzerland, Jan. 2007, 299 pp. (in French)

13. Fernández Ruiz, M.; Muttoni, A.; and Gambarova, P. G., "Analytical Modeling of the Pre- and Post-Yield Behavior of Bond in Reinforced Concrete," Journal of Structural Engineering, American Society of Civil Engineers, V. 133, No. 10, Oct. 2007, pp. 1364-1372.

14. fib, "Bond of Reinforcement in Concrete," Bulletin No. 10, Fédération Internationale du Béton, Lausanne, Switzerland, 2000, 427 pp.

15. Tepfers, R., "A Theory of Bond Applied to Overlapped Tensile Reinforcement Splices for Deformed Bars," Publication 73:2, Chalmers University of Technology, Göteborg, Sweden, 1973, 328 pp.

16. Fernández Ruiz, M.; Muttoni, A.; and Gambarova, P. G., "A Reevaluation of Test Data on Bond in RC by Means of FE Modelling," Studies and Researches, V. 27, Dec. 2007, pp. 113-134.

17. Muttoni, A., and Fernández Ruiz, M., "Shear Strength of Members without Transverse Reinforcement as Function of Critical Shear Crack Width,” ACI Structural Journal, V. 105, No. 2, Mar.-Apr. 2008, pp. 163-172.

\section{APPENDIX}

In this Appendix, Eq. (5) is used together with the affinity hypothesis of bond ${ }^{13,16}$ to estimate the splitting tensile stresses and to determine the failure load in arch-shaped 
members. To do so, it can be noted that both the steel stress and bond stresses can be written as a function of the bar strains. With respect to the steel stress $\varepsilon_{s}$, it can be related to the strains of the bar $\varepsilon_{s}$ for a given constitutive law of the steel. The bond stress $\tau_{b}$ can at its turn be referred to the steel strain if the slip distribution along the bar is affine for different load levels. The authors have proven this to be true for bars with sufficient development length. ${ }^{13,16}$ Prior to yielding of the reinforcement, the following expressions can thus be adopted ${ }^{13}$ (refer to Fig.11(a))

$$
\begin{gathered}
\sigma_{s}=E_{s} \cdot \varepsilon_{s} \\
\tau_{b}=3 f_{c t} \sqrt{\frac{\varepsilon_{s}}{\varepsilon_{y}}}
\end{gathered}
$$

where $E_{s}$ is Young's modulus, $\varepsilon_{s}$ is the maximum bar strain (strain at crack location), and $\tau_{y}$ is the yield strain of the steel. Introducing these expressions into Eq. (5) results in

$$
\sigma_{t}=\frac{E_{s} \cdot \pi / 4 \cdot d_{b}^{2}}{b_{e f} \cdot R} \varepsilon_{s}+\frac{3 \tan (\alpha) \cdot d_{b} \cdot f_{c t}}{b_{e f} \cdot \sqrt{\varepsilon_{y}}} \sqrt{\varepsilon_{s}}
$$

where the following hypotheses can further be adopted:

1. At failure $\sigma_{t}=\eta f_{c t}$, where for concrete strengths up to $50 \mathrm{MPa}$ (7250 psi), the parameter $\eta$ can be adopted as 0.8 to account for concrete brittleness in tension.

2. The angle of the bond struts $\alpha$ (refer to Fig. 3(b)) defines the relationship between bond stress and transverse tensile stresses. For low levels of strain in the reinforcing bar, bond is mostly activated by chemical adhesion ${ }^{14}$ (without splitting stresses), whereas for significant levels of strain, bond is mostly activated by local crushing of the concrete close to the ribs and by the development of tensile splitting rings ${ }^{14}$ (refer to Fig. 3). Due to this reason, a linear relationship between $\alpha$ and $\varepsilon_{s}$ is proposed prior to yielding, varying from 0 to 40 degrees at yielding for the adopted bond law.

3. For the chosen failure plane (refer to Fig. 8 and 12(a)): $b_{e f}=s-d_{b}$, where $s$ is the distance between bars. In addition, it should be considered that $b_{e f} \leq\left(6 d_{b} ; 4 c\right)$ to account for other possible failure surfaces (refer to Fig. 12(b)).

4. In the presence of bundled bars (two or more bars grouped together) or lap splices, Eq. (9) can be used by considering an equivalent bar whose cross-sectional area is equal to the sum of those of the bundled bars.

$$
d_{b}^{*}=\sqrt{\sum_{i=1}^{n} d_{b i}^{2}}
$$

In addition, in the presence of lap splices or in case of no perpendicular reinforcement to the bundled bars is provided, the term accounting for bond stresses $\left(\sigma_{t b}\right.$, second term of Eq. (9)) has to be multiplied by a factor $\kappa_{b}=d_{b}{ }^{*} / d_{b}$ to account for the local increase of bond splitting stresses. For lap splices, the value of coefficient $\kappa_{b}$ is thus typically $\sqrt{ } 2$.

With respect to the behavior after yielding of the longitudinal bars, it can also be characterized as a function of the steel strain by adopting a softening slope for bond stresses (refer to Fig. 11(a)), as demonstrated ${ }^{13}$ for straight reinforced ties. The mechanical behavior after yielding of the reinforcement on arch-shaped members, however, is somewhat more complicated than for straight reinforced ties. This is due to the wedging action exerted by the ribs of deformed bars, which are in contact with the concrete cover at the intrados face of the bar. Thus, angle $\alpha$ can increase after yielding (refer to Fig. 11(b)), leading to spalling of the cover (as observed in the tests). This limits the ductility of plastic hinges and its relevance for plastic analyses (where a certain rotation capacity is required to develop the various plastic hinges of the structure). Design implications are discussed in the section "code-like formulation."

With reference to the use of Eq. (9) for predicting cover spalling failures of arch-shaped members, it can be easily carried out by estimating the flexural reinforcement strains at failure. This can be done prior to yielding by assuming a perfectly elastic behavior of concrete in compression with no tensile strength (refer to Fig. 13). The bending moment at failure can thus be calculated as

\section{(a)}

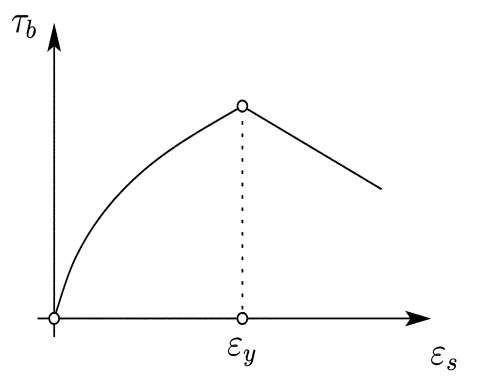

(b)

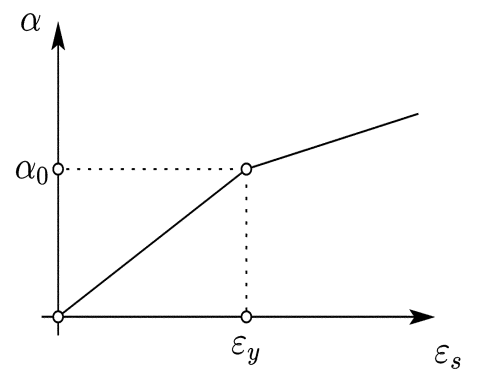

Fig. 11-Adopted laws as function of reinforcing steel strains for: (a) bond stresses; and (b) bond struts angle $(\alpha \leq \pi / 2)$.

(a)

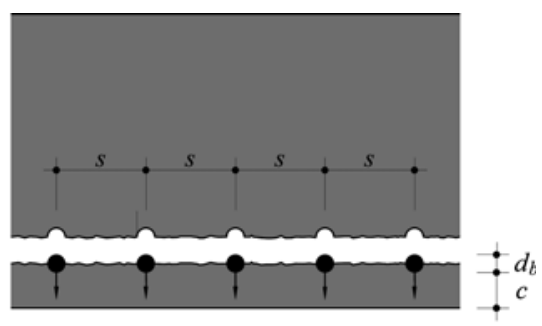

(b)

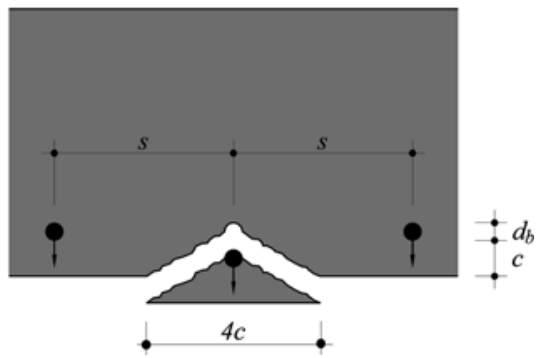

Fig. 12-Failure surfaces: (a) for small s/c (bar spacing/ concrete cover) ratios; and (b) for large s/c ratios. 


$$
M_{R}=E_{s} \varepsilon_{s} \rho b d\left(d-\frac{x}{3}\right) \leq M_{y}
$$

where $x$ is the depth of the compression zone, whose value is

$$
x=d \rho \frac{E_{s}}{E_{c}}\left(\sqrt{1+\frac{2 E_{c}}{\rho E_{s}}}-1\right)
$$

If failure develops after yielding of the reinforcement, the strength is governed by the plastic bending strength. The bending strength in these cases results (Fig. 13(c))

$$
M_{y}=\rho b d^{2} f_{y}\left(1-\frac{\rho f_{y}}{2 f_{c}}\right)
$$

In the paper, Eq. (11) and (13) are used in combination with Eq. (9) to calculate the failure loads of the tests

\begin{tabular}{|c|c|c|c|c|c|c|c|c|c|c|c|c|}
\hline Specimen & $\begin{array}{c}b, \\
\text { mm (in.) }\end{array}$ & $\begin{array}{c}d, \\
\text { mm (in.) }\end{array}$ & $\begin{array}{c}R, \\
\mathrm{~mm} \text { (in.) }\end{array}$ & $\begin{array}{c}d_{b}, \\
\text { mm (in.) }\end{array}$ & $\begin{array}{c}s, \\
m m(\text { in.) }\end{array}$ & $n_{b}$ & $\begin{array}{c}c, \\
\text { mm (in.) }\end{array}$ & $\begin{array}{c}f_{c}, \\
\operatorname{MPa}(\mathrm{psi})\end{array}$ & $\begin{array}{c}f_{c t}, \\
\mathrm{MPa}(\mathrm{psi})\end{array}$ & $\begin{array}{c}Q_{\text {test }}, \\
\mathrm{kN} \text { (kips) }\end{array}$ & $\begin{array}{c}Q_{\text {calc }}, \\
\mathrm{kN} \text { (kips) }\end{array}$ & $\begin{array}{l}Q_{\text {test }} / \\
Q_{\text {calc }}\end{array}$ \\
\hline $\mathrm{ECP} 1^{12}$ & $300(11.8)$ & $347(13.7)$ & $3553(140)$ & $26(1.02)$ & $100(3.93)$ & 1 & $40(1.57)$ & $37.4(5420)$ & $3.36(486)$ & $432(97.1)$ & 418 (93.9) & 1.03 \\
\hline $\mathrm{ECP} 2^{12}$ & $300(11.8)$ & 349 (13.7) & $3551(140)$ & $22(0.87)$ & $0(3.93)$ & 1 & $(1.57)$ & $40.9(5930)$ & $3.56(515)$ & $324(72.8)$ & $320(71.9)$ & 1.01 \\
\hline $\mathrm{ECP}^{12}$ & $300(11.8)$ & $350(13.8)$ & $3550(140)$ & $20(0.79)$ & $00(3.93)$ & 1 & $(1.57)$ & $41.7(6050)$ & $3.61(523)$ & 287 (64.5) & $284(63.8)$ & 1.01 \\
\hline $\mathrm{ECP} 4^{12}$ & $300(11.8)$ & $351(13.8)$ & $3549(140)$ & $18(0.71)$ & $100(3.93)$ & 1 & $40(1.57)$ & $33.9(4920)$ & $3.14(455)$ & $231(51.9)$ & $248(55.7)$ & 0.93 \\
\hline $\mathrm{ECP5}^{12}$ & $300(11.8)$ & $349(13.7)$ & $3551(140)$ & $22(0.87)$ & $100(3.93)$ & 2 & $40(1.57)$ & $38.4(5570)$ & $3.41(494)$ & $237(53.7)$ & $200(44.9)$ & 1.18 \\
\hline $\mathrm{ECP}^{12}$ & $300(11.8)$ & $349(13.7)$ & $3551(140)$ & $22(0.87)$ & $100(3.93)$ & 2 & $40(1.57)$ & $35.5(5150)$ & $3.24(469)$ & $197(44.3)$ & $199(44.7)$ & 0.99 \\
\hline $2.1^{2}$ & $1000(39.4)$ & $139(5.47)$ & $1111(43.8)$ & $12(0.47)$ & $200(7.88)$ & 2 & $5(0.59)$ & $25.8(3730)$ & $2.62(380)$ & $121(27.2)$ & $109(24.5)$ & 1.11 \\
\hline $2.2^{2}$ & $1000(39.4)$ & $139(5.47)$ & $1111(43.8)$ & $12(0.47)$ & $100(3.93)$ & 1 & $15(0.59)$ & $30.1(4360)$ & $2.90(420)$ & $180(40.5)$ & $183(41.1)$ & 0.98 \\
\hline $2.3^{2}$ & $1000(39.4)$ & $139(5.47)$ & $1111(43.8)$ & $12(0.47)$ & $200(7.88)$ & 2 & $15(0.59)$ & $22.4(3250)$ & $2.38(345)$ & $140(31.5)$ & $124(27.8)$ & 1.13 \\
\hline $2.4^{2}$ & $1000(39.4)$ & $139(5.47)$ & $1111(43.8)$ & $12(0.47)$ & $100(3.93)$ & 1 & $15(0.59)$ & $24.0(3480)$ & $2.50(362)$ & $169(37.9)$ & $168(37.7)$ & 1.01 \\
\hline $2.5^{2}$ & $1000(39.4)$ & $139(5.47)$ & $1111(43.8)$ & $12(0.47)$ & $100(3.93)$ & 1 & $15(0.59)$ & $24.4(3540)$ & $2.52(365)$ & $156(35.0)$ & $168(37.7)$ & 0.93 \\
\hline $2.6^{2}$ & $1000(39.4)$ & $139(5.47)$ & $1111(43.8)$ & $12(0.47)$ & $200(7.88)$ & 2 & $30(1.18)$ & $23.9(3460)$ & $2.49(360)$ & $121(27.2)$ & $109(24.5)$ & 1.11 \\
\hline $2.7^{2}$ & $1000(39.4)$ & $139(5.47)$ & $1111(43.8)$ & $12(0.47)$ & $100(3.93)$ & 2 & $15(0.59)$ & $24.7(3580)$ & $2.54(368)$ & $171(38.4)$ & $197(44.2)$ & 0.87 \\
\hline $2.8^{2}$ & $1000(39.4)$ & $139(5.47)$ & $1111(43.8)$ & $12(0.47)$ & $50(1.97)$ & 1 & $15(0.59)$ & $24.0(3480)$ & $2.50(362)$ & $191(42.9)$ & $239(53.7)$ & 0.80 \\
\hline $2.9^{2}$ & $1000(39.4)$ & $139(5.47)$ & $1111(43.8)$ & $12(0.47)$ & $200(7.88)$ & 1 & $15(0.59)$ & $24.1(3490)$ & $2.50(362)$ & $101(22.7)$ & $90(20.2)$ & 1.12 \\
\hline $2.10^{2}$ & $1000(39.4)$ & $140(5.51)$ & $1111(43.8)$ & $10(0.39)$ & $50(1.97)$ & 1 & $15(0.59)$ & $31.4(4550)$ & $2.99(433)$ & $210(47.2)$ & $222(49.9)$ & 0.95 \\
\hline $2.11^{2}$ & $1000(39.4)$ & $140(5.51)$ & $1111(43.8)$ & $10(0.39)$ & $100(3.93)$ & 1 & $15(0.59)$ & $25.0(3620)$ & $2.56(371)$ & $138(31.0)$ & $130(29.2)$ & 1.06 \\
\hline $2.12^{2}$ & $1000(39.4)$ & $139(5.47)$ & $1111(43.8)$ & $12(0.47)$ & $200(7.88)$ & 2 & $15(0.59)$ & $38.4(5560)$ & $3.41(494)$ & $112(25.2)$ & $110(24.7)$ & 1.02 \\
\hline $2.13^{2}$ & $1000(39.4)$ & $140(5.51)$ & $1111(43.8)$ & $10(0.39)$ & $200(7.88)$ & 2 & $15(0.59)$ & $21.0(3040)$ & $2.28(330)$ & $81(18.2)$ & 88 (19.8) & 0.92 \\
\hline $2.14^{2}$ & $1000(39.4)$ & $140(5.51)$ & $1111(43.8)$ & $10(0.39)$ & $100(3.93)$ & 2 & $15(0.59)$ & $25.6(3710)$ & $2.61(669)$ & $158(35.5)$ & $171(38.4)$ & 0.92 \\
\hline $2.15^{2}$ & $1000(39.4)$ & $139(5.47)$ & $1111(43.8)$ & $12(0.47)$ & $200(7.88)$ & 2 & $15(0.59)$ & $42.1(6100)$ & $3.63(526)$ & $151(494)$ & $125(28.1)$ & 1.21 \\
\hline $2.16^{2}$ & $1000(39.4)$ & $140(5.51)$ & $1111(43.8)$ & $10(0.39)$ & $200(7.88)$ & 1 & $15(0.59)$ & $18.9(2740)$ & $2.13(308)$ & $75(16.8)$ & $66(14.8)$ & 1.13 \\
\hline $2.17^{2}$ & $1000(39.4)$ & $140(5.51)$ & $1111(43.8)$ & $10(0.39)$ & $200(7.88)$ & 1 & $15(0.59)$ & $24.4(3540)$ & $2.52(365)$ & $79(17.7)$ & $37(8.31)$ & 1.18 \\
\hline $\mathrm{A} 1^{6}$ & $350(13.8)$ & $565(22.2)$ & $3950(155)$ & $16(0.63)$ & 44 (1.73) & 1 & $50(1.97)$ & $23.4(3400)$ & $2.46(360)$ & $479(107)$ & $440(98.9)$ & 1.09 \\
\hline $\mathrm{A} 2^{6}$ & $350(13.8)$ & $565(22.2)$ & $3950(155)$ & $16(0.63)$ & 44 (1.73) & 1 & $50(1.97)$ & $23.4(3400)$ & $2.46(360)$ & $460(103)$ & $440(98.9)$ & 1.04 \\
\hline $\mathrm{A} 3^{6}$ & $350(13.8)$ & $565(22.2)$ & $3950(155)$ & $16(0.63)$ & 44 (1.73) & 1 & $50(1.97)$ & $23.4(3400)$ & $2.46(360)$ & $451(101)$ & $440(98.9)$ & 1.02 \\
\hline $\mathrm{Aq}^{6}$ & $350(13.8)$ & $565(22.2)$ & $3950(155)$ & $16(0.63)$ & $44(1.73)$ & 1 & $50(1.97)$ & $23.4(3400)$ & $2.46(360)$ & $470(105)$ & $440(98.9)$ & 1.07 \\
\hline $\mathrm{B} 1^{6}$ & $350(13.8)$ & $565(22.2)$ & $3950(155)$ & $16(0.63)$ & $88(3.47)$ & 2 & $50(1.97)$ & $26.2(3790)$ & $2.65(380)$ & 439 (98.6) & $441(99.1)$ & 1.00 \\
\hline $\mathrm{B} 2^{6}$ & $350(13.8)$ & $565(22.2)$ & $3950(155)$ & $16(0.63)$ & $88(3.47)$ & 2 & $50(1.97)$ & $26.2(3790)$ & $2.65(380)$ & $476(107)$ & $441(99.1)$ & 1.08 \\
\hline $\mathrm{B} 3^{6}$ & $350(13.8)$ & $565(22.2)$ & $3950(155)$ & $16(0.63)$ & $88(3.47)$ & 2 & 50 (1.97) & $26.2(3790)$ & $2.65(380)$ & 407 (91.5) & $441(99.1)$ & 0.92 \\
\hline $\mathrm{Bq}^{6}$ & $350(13.8)$ & $565(22.2)$ & $3950(155)$ & $16(0.63)$ & $88(3.47)$ & 2 & 50 (1.97) & $26.2(3790)$ & $2.65(380)$ & $516(116)$ & 519 (116.6) & 0.99 \\
\hline $\mathrm{C} 1^{6}$ & $350(13.8)$ & $565(22.2)$ & $3950(155)$ & $16(0.63)$ & $175(6.9)$ & 4 & $50(1.97)$ & $26.1(3780)$ & $2.64(380)$ & $431(96.8)$ & $415(93.2)$ & 1.04 \\
\hline $\mathrm{C} 2^{6}$ & $350(13.8)$ & $565(22.2)$ & $3950(155)$ & $16(0.63)$ & $175(6.9)$ & 4 & $50(1.97)$ & $26.1(3780)$ & $2.64(380)$ & $469(105)$ & $415(93.2)$ & 1.13 \\
\hline $\mathrm{C} 3^{6}$ & $350(13.8)$ & $565(22.2)$ & $3950(155)$ & $16(0.63)$ & $175(6.9)$ & 4 & $50(1.97)$ & $26.1(3780)$ & $2.64(380)$ & $398(89.4)$ & $415(93.2)$ & 0.96 \\
\hline \multirow{2}{*}{\multicolumn{12}{|c|}{ Average }} & 1.03 \\
\hline & & & & & & & & & & & & 0.09 \\
\hline
\end{tabular}
presented in Table 2.

Table 2-Comparison of theoretical model and test results
Fig. 13-Strength of arch-shaped member subjected to bending: (a) member and investigated section; (b) assumed behavior prior to yielding of reinforcement; and (c) plastic behavior (after yielding of tensile reinforcement). (b)

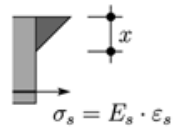

(c)

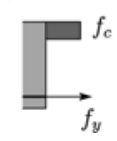

